\title{
WAVE ATTENUATION IN MANGROVE FORESTS; FIELD DATA OBTAINED IN TRANG, THAILAND
}

\author{
Erik Horstman ${ }^{1,2}$, Marjolein Dohmen-Janssen ${ }^{1}$, Pedro Narra ${ }^{3}$, Niels-Jasper van den Berg ${ }^{1}$, \\ Martijn Siemerink ${ }^{1}$, Thorsten Balke ${ }^{2,4}$, Tjeerd Bouma ${ }^{2,5}$ and Suzanne Hulscher ${ }^{1}$
}

\begin{abstract}
Mangroves thrive in sheltered intertidal areas in the tropics and sub-tropics. Due to this position at the interface between land and sea, mangroves play an important role in the attenuation of waves. Dissipation of wave energy in mangrove forests is an interesting feature from the viewpoint of coastal protection. Nevertheless, field data are sparse and modeling attempts reveal the need for additional data. This paper presents the results of an extensive field campaign, lasting 6 months, in mangroves along the Andaman coast of Trang Province in southern Thailand. Wave attenuation has been studied along two contrasting transects with different elevation and vegetation characteristics and different orientations towards the Andaman Sea. Along the Kantang transect, which is mostly exposed to swell waves, vegetation densities increased from 4.5 to 9.3 volume-\%o along the transect and on average $63 \%$ of the incident wave energy was attenuated over a distance of $246 \mathrm{~m}$. Along the Palian transect, mostly exposed to sea waves instead, vegetation increased from 4.3 to 19 volume-\%o and $72 \%$ of the incident wave energy was attenuated over this $98 \mathrm{~m}$ transect. It was found that standardized wave attenuation correlates well with incident wave energy, when attenuation is analyzed per vegetation zone. Energy reduction rates of these zones, defined by the gradient of the correlations between the standardized wave attenuation and incident wave energy, are found to increase significantly with vegetation density. Consistently, wave reduction rates, expressing the gradient of the correlation between wave height reduction and incident wave heights, are found to be $0.001-0.014$ for the study sites and also show a significant and increasing trend with vegetation densities.
\end{abstract}

Keywords: mangroves; wave attenuation; field data; Thailand

\section{INTRODUCTION}

Mangroves form a key-ecosystem in the intertidal area of tropical and sub-tropical coastlines. Mangrove vegetation consists of salt tolerant trees and shrubs, usually thriving between mean sea level and high water spring level. They are able to resist the hydrodynamic forces faced at sheltered coastlines such as estuaries and lagoons (Augustinus, 1995). Due to their location and persistence, mangroves play an important role in wave attenuation (Vo-Luong and Massel, 2006; Quartel et al., 2007) and in coastal stabilization (Augustinus, 1995; Anthony, 2004; Van Santen et al., 2007; Alongi, 2008). Mangroves are even said to have had a positive contribution to the safety of coastal areas during the Indian Ocean tsunami in 2004 (Danielsen et al., 2005). Next to these physical benefits to tropical coastal areas, mangroves are an outstanding habitat for numerous species of fish, insects, birds, crustaceans, reptiles and mammals. Despite this key-function of mangroves in the intertidal area, they are in rapid decline. A recent analysis found that the global mangrove extent in 2000 was 13.8 million hectare (Giri et al., 2011) while in 1980 there was still about 18.8 million hectare (FAO, 2007), i.e. a $27 \%$ decrease of the world's mangrove area in 20 years only. Although annual mangrove losses are slowing down, estimated loss rates of $0.66 \%$ for the five years to 2005 are still substantial (FAO, 2007; Spalding et al., 2010). Therefore there is an urgent need to unravel the physical contribution of mangroves to coastal safety in order to increase awareness of the need for mangrove preservation.

Unraveling dissipation of wave energy in coastal mangroves by field and laboratory studies has only gained attention recently (Alongi, 2009). Due to the inaccessibility of (natural) mangrove forests, a limited number of field studies has been executed in mangroves in Vietnam, Australia and Japan mainly (Brinkman et al., 1997; Mazda et al., 1997a; Mazda et al., 2006; Vo-Luong and Massel, 2006; Quartel et al., 2007; Bao, 2011). Wave attenuation by mangroves can be parameterized by calculating a bulk roughness parameter comprising both vegetation induced drag forces and bottom friction (Mazda et al., 1997b; Quartel et al., 2007). Recent modeling studies are directly taking account of the vegetation induced drag forces, calculated by simplifying mangrove vegetation into one or several layers of cylinders (Vo-Luong and Massel, 2008; Suzuki et al., 2012). This approach requires site specific information on vegetation characteristics such as stem and root diameters, distinct vegetation

\footnotetext{
${ }^{1}$ Water Engineering \& Management, University of Twente, P.O. Box 217, 7500 AE Enschede, The Netherlands ${ }^{2}$ Singapore-Delft Water Alliance, National University of Singapore, Engineering Drive 2, 117576 Singapore

${ }^{3}$ Dep. de Engenharia Civil, Universidade de Aveiro, Campus Universitário de Santiago, 3810-193 Aveiro, Portugal

${ }^{4}$ Marine \& Coastal Systems, Deltares, P.O. Box 177, 2629 HD Delft, The Netherlands

${ }^{5}$ Dep. of Spatial Ecology, Royal Netherlands Institute for Sea Research NIOZ, P.O. Box 140, 4400 AC Yerseke, The Netherlands
} 
layers, densities and (bulk) drag coefficients. Depending on the available field data, these models can be calibrated in the bulk drag coefficient or in a single vegetation factor including all vegetation parameters (Suzuki et al., 2012). Each of these parameters is sensitive to changes in vegetation and hydrodynamic conditions and hence requires accurate calibration for any situation.

Field data comprising measurements of both hydrodynamics (i.e. wave heights and water depths) and vegetation parameters are indispensable for further development of these models (McIvor et al., 2012; Möller, 2012). However, both factors are changing from site to site, depending on local geography, hydrodynamic boundary conditions and the characteristics of the mangrove vegetation. Inherent to wave attenuation studies, differences in hydrodynamic conditions are often included. On contrary, vegetation characteristics are hardly ever taken into account explicitly. Most field studies to date only include rather qualitative information of local vegetation patterns (Brinkman, 2006; VoLuong and Massel, 2006; Quartel et al., 2007). Mazda et al. (1997b) made a start with identifying relevant vegetation parameters and quantifying the volume-percentage of mangrove biomass in the water. This concept will be further elaborated in the present paper.

This paper makes a start bridging the gap by presenting the findings of an extensive field campaign combining hydrodynamic measurements and the collection of geographic and vegetation data. These data have been collected at two study sites showing different vegetation characteristics and zonation. Along each transect wave data have been collected during several instrument deployments (each lasting two weeks) during a period of five months. First, the differences in vegetation characteristics facilitate the analysis of the impact of different vegetation parameters (e.g. root type, tree density) on wave attenuation. Second, by covering a period of several months, wave data include different tidal and meteorological conditions. This could enhance insight in the behavior of wave dissipation in mangroves under changing hydrodynamic conditions (i.e. water depths and wave heights).
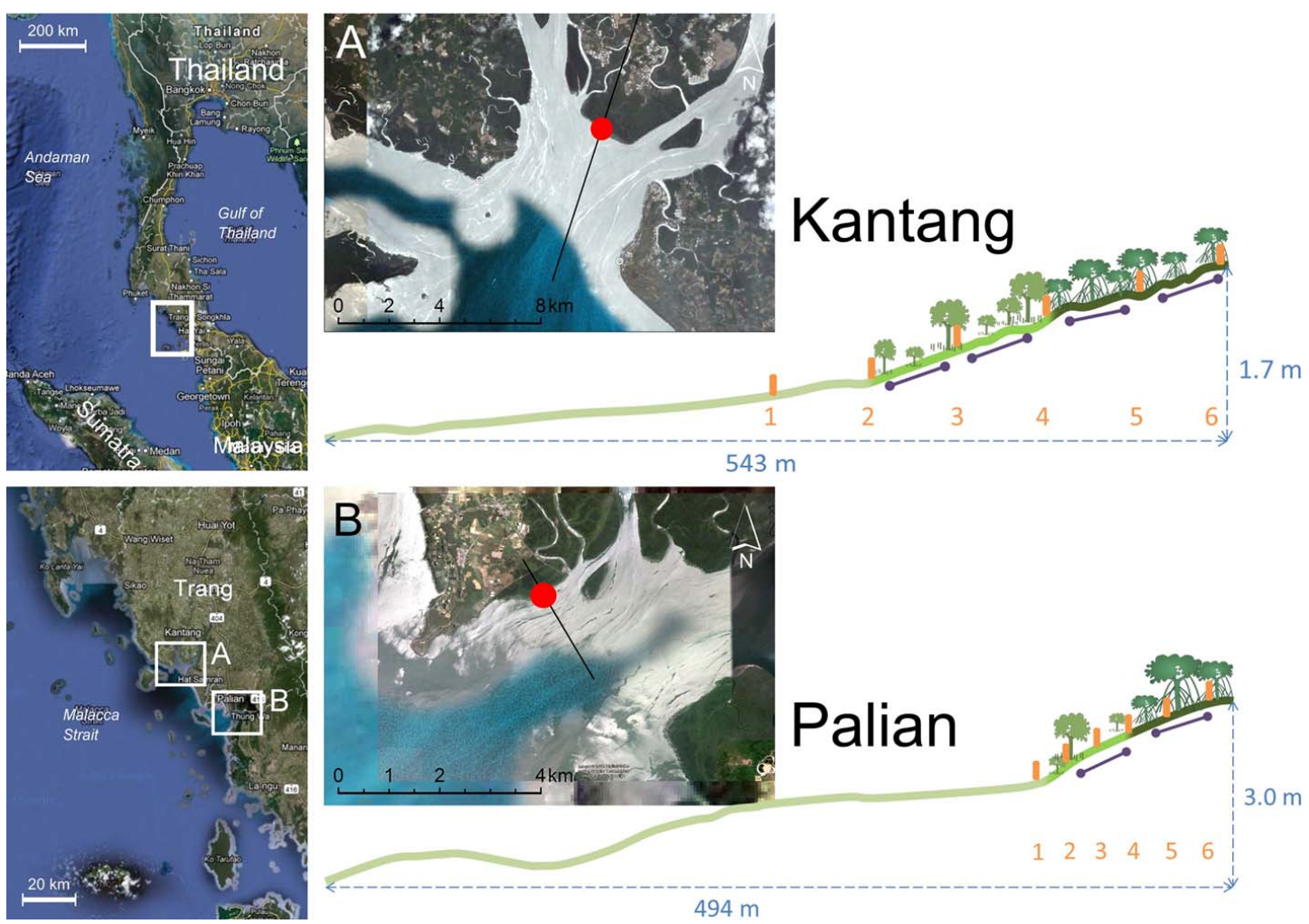

Figure 1. Location and topography of the wave transects: (A) southern Thailand; (B) The coast of Trang Province featuring two estuaries; (C) the estuary of the Trang River near Kantang village; (D) the Palian River estuary near Palian village. Black lines in maps $C$ and $D$ indicate the orientation of the wave transects and the red dots mark the location of the cross-sections of the Kantang and Palian wave transects as plotted next to map C and D respectively. Within the cross-sections different shades of green indicate subsequent vegetation zones (pale green $=$ mudflat; light green $=$ sparse Avicennia/Sonneratia forest; dark green $=$ dense Rhizophora forest), numbers indicate the positions of wave sensors (vertical orange bars) and purple bars indicate vegetation survey plots. 
This paper first presents the study site and the two transects along which wave attenuation has been studied. Subsequently, measurement methods are introduced for quantifying vegetation and wave data along each of these transects. The methodology section also describes how obtained wave data have been processed into interpretable wave statistics. The resulting vegetation characteristics and wave statistics are presented in the results section, where these two variables will be correlated as well. These new findings are compared to some previous studies in the discussion. The main conclusions are summarized in the final section.

\section{STUDY SITES}

The study sites are located at the east coast of southern Thailand, in Trang Province (Figure 1AB). This coast is part of the convoluted Thai Andaman coast, consisting of many embayments, islands and islets offering a perfect habitat to mangroves. The Andaman coast hosts about $80 \%$ of the 244,000 hectare of Thai mangroves [FAO, 2007]. Although the Thai Andaman coast was severely struck by the 2004 Indian Ocean tsunami, the study sites are unaffected due to the tip of Sumatra (Banda Aceh) and the many islets sheltering this part of the Andaman Sea from incoming waves from the Indian Ocean.

The two wave transects that have been defined for data collection are located in the estuary of the Trang River near Kantang village (Figure 1C) and in the estuary of the Palian River near Palian village (Figure 1D) respectively. Both transects feature a sparsely vegetated forest front and a densely vegetated back forest. The transects show contrasts in topology and vegetation: (I) the bed slope of the Palian transect is about twice as steep as the slope of the Kantang Transect (also within the forest); (II) vegetation zones are narrower along the Palian transect than along the Kantang transect; (III) larger vegetation densities are found in the Palian back forest; and (IV) the orientation of the transects with respect to the Andaman Sea is different, giving rise to different wave climates. Both transects are oriented perpendicular to the local coastline and parallel to the major direction of wave propagation into the mangroves. Hence the Kantang transect is directed southwest towards the Andaman Sea (Figure 1C) while the Palian transect is directed towards the southeast across the Palian River estuary (Figure 1D). The transects are restricted to the front few 100's of meters of the rather extensive mangrove forests in both estuaries as attenuation of hydrodynamic energy largely occurs in this part of the forest.

The study sites are tide dominated (Woodroffe, 1992) being exposed to a mixed semi-diurnal tide with a tidal amplitude of $3.5 \mathrm{~m}$. Wave climate in this region is strongly influenced by the annual monsoons. The northeast monsoon prevails from October to February, southwest monsoons generate the highest waves at the Andaman coast and prevail from May to October. The present data have been collected from December 2010 to May 2011 and hence mainly cover the relatively quiet conditions of the northeast monsoon. However, during the last week of March 2011, the Andaman coast was struck by severe storms giving rise to increased wave heights at the coasts and causing severe floods inland.

\section{METHODOLOGY}

\section{Vegetation Survey}

Along the wave transects, representative vegetation plots of $20 \times 20 \mathrm{~m}^{2}$ have been selected. Locations of these plots along the transects are indicated in Figure 1C-D by the purple bars. The vegetation survey is executed slightly different for the sparsely vegetated front forest than for the heavily vegetated back forest.

In the forest fringe zone Avicennia and Sonneratia trees are predominant. The root systems of Avicennia and Sonneratia trees feature pneumatophores, the pencil roots popping out of the forest floor. These trees are classified according to their size. The trunk or stem diameter has been measured at breast height (i.e. $1.50 \mathrm{~m}$ ) or, when the tree is too small, at one third of the height of the young tree. These diameters are categorized into five groups: 0-10 mm, 10-25 mm, 25-100 mm, 100-200 mm and $200 \mathrm{~mm}$ and larger. Per category, for one representative tree additional data has been collected: the stem diameter has been measured at $0.1 \mathrm{~m}, 0.5 \mathrm{~m}, 1.0 \mathrm{~m}, 1.5 \mathrm{~m}$ and $2.0 \mathrm{~m}$ above the bed and diameters of branches are included as well. Rhizophora vegetation in the forest fringe is analyzed in a slightly different way (since there were much less Rhizophora trees than Avicennia and Sonneratia trees present and because stem diameter is a rather complex measure for these trees). All Rhizophora trees in the plot are counted and root characteristics are measured for one average tree (since their variability is rather small in this zone). Diameters of all roots, stems and branches of this average tree have been measured at $0.1 \mathrm{~m}, 0.5 \mathrm{~m}, 1.0 \mathrm{~m}$ and $2.0 \mathrm{~m}$ above the bed as well. 
Rhizophora vegetation is predominant in the back forest. Rhizophora trees have the typical stilt root systems. In the back forest plots, all trees have been counted and root characteristics have been measured for a small, an average and a large tree (here Rhizophora tree sizes are much more variable than in the fringe forest). These small and large trees were selected to be representative for the $20 \%$ smallest trees and the $20 \%$ largest trees respectively. The average tree represented the remaining trees in the plot. Further characterization of these trees is the same as of those in the forest fringe; diameters of all roots, stems and branches of this average tree have been measured at $0.1 \mathrm{~m}, 0.5 \mathrm{~m}, 1.0 \mathrm{~m}$ and 2.0 $\mathrm{m}$ above the bed. Avicennia and Sonneratia trees in the back forest are treated the same as Rhizophora trees. Their total number has been counted, and the same measures have been taken for a small, an average and a large tree.

Within each plot, seedlings (i.e. single stemmed tree saplings) are counted separately. The diameter of one average seedling per plot has been measured at the same levels above the bed. For dead trees occurring in any of the plots, the average height and diameter has been included too. Finally, three subplots of $0.5 \mathrm{~m} \times 0.5 \mathrm{~m}$ are allocated within each vegetation plot representing a low, average and high pneumatophore density. Within these subplots, the total number of pneumatophores is counted. Height and diameter of the pneumatophores is measured for 20 randomly chosen pneumatophores per subplot.

Vegetation data is merged by first calculating the total horizontal area of vegetation elements in each of the vegetation plots at different levels above the bed. Subsequently, the volume of vegetation within the first meter above the forest bed is calculated and this is expressed as a relative vegetation volume (volume-\%o), similar to the volumetric vegetation parameter deployed by Mazda et al. (1997b).

\section{Hydrodynamic Data Collection}

Six high frequency pressure sensors (MacroWave, Coastal Leasing Inc., Figure 2) have been deployed for collecting wave data in the mangroves. These sensors are capable of collecting pressure data independently for periods of up to several weeks (depending on sampling frequency and battery quality). Sampling rates of the pressure sensors were set to $10 \mathrm{~Hz}$, with a burst length of $2^{\wedge} 12$ (=4096) samples and a burst interval of 20 minutes. In order to be able to start data collection at shallow water depths, the instruments have been buried with the sensors leveled at 5-7 cm above the bed (Figure 2).
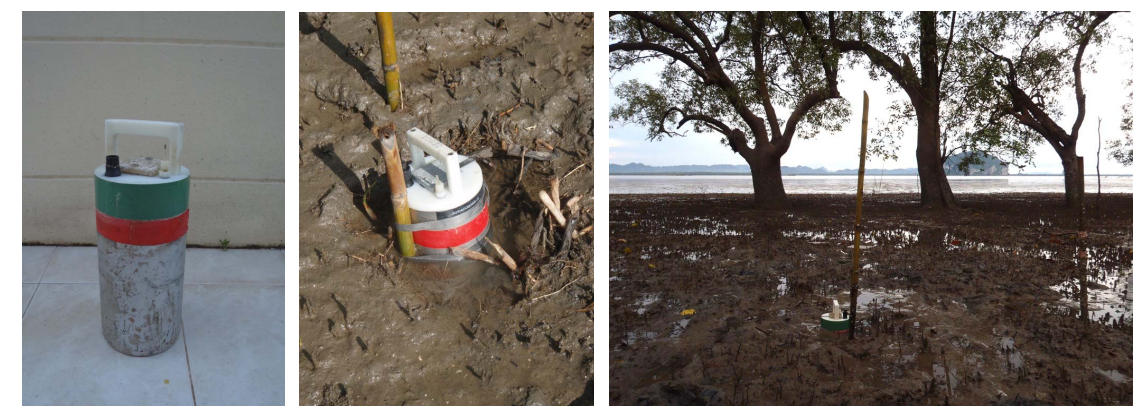

Figure 2. MacroWave wave sensors have been deployed for obtaining wave attenuation data (left). The instruments have been buried to start data observation at shallow water depths (middle). Deployment of a wave sensor within the Avicennia zone of the Palian transect (right).

The wave sensors have been deployed at fixed locations along the wave transects, as indicated in Figure 1C-D. Positioning of the instruments along the transects was related to the vegetation characteristics of the sites. Two sensors were located at the subsequent interfaces between the mudflat, the sparsely vegetated forest front and the denser vegetated back forest. The four remaining sensors were located within these specific zones. Due to the different topography of the sites, distances between the instrument locations were about $50 \mathrm{~m}$ along the Kantang transect (Figure 1C) and about $20 \mathrm{~m}$ at the Palian transect (Figure 1D).

Wave sensors have been deployed three times along each of the transects and single deployments lasted for 2 to 6 weeks. Due to poor battery performance, some sensors stopped collecting data before the planned end dates. Next, sensors stopped working randomly during some of the deployments (sometimes after a few days already). Hence the data collected shows some gaps in time and space. For each transect the two best deployments that delivered data for most instruments have been selected for presentation in this paper. For the Kantang transect, selected wave data have been collected from 7 to 
20 March and from 24 March to 14 April 2011. For the Palian transect, wave measurements took place from 8 December 2010 to 19 January 2011 and from 17 April until 2 May 2011.

Next to these high frequency wave sensors, low frequency pressure (and temperature) loggers (Sensus Ultra, ReefNet Inc.) have been deployed continuously during the field campaign for collecting tidal data with a sampling rate of once every 5 minutes. These loggers were deployed at position 2 along the Kantang transect and between positions 1 and 2 at the Palian transect (Figure 1C-D).

\section{Data Processing}

Obtained pressure data are corrected for the atmospheric pressure and subsequently transformed into water depths with the specific weight $(\rho g)$ of the water. From meteorological data for the period of the field campaign it was derived that the average atmospheric pressure was $1008 \mathrm{hPa}$ with daily extremes up to $5 \mathrm{hPa}$ lower/higher. These fluctuations in ambient pressure are irrelevant on the time scale of the waves though. Specific gravity has been calculated from the site specific gravitational acceleration and water density: $9.78 \mathrm{~m} / \mathrm{s}^{2}$ and $1004 \mathrm{~kg} / \mathrm{m}^{3}$ respectively. This density has been calculated for a water temperature varying between $26^{\circ}$ and $33^{\circ}$ Celsius (observed by the Sensus Ultra divers) and a salinity of 9-13 PPT (analyzed from water samples).

Fourier analysis has subsequently been conducted to transform the obtained water depth time series into an energy density spectrum for every single burst. This analysis consists of 6 steps, based on Hegge and Masselink (1996):

1. De-trending the signal to overcome within-burst tidal water level fluctuations.

2. Applying a Hann-taper $w$ for preventing leakage of spectral density from large peaks:

$$
w(n)=0.5\left(1-\cos \frac{2 \cdot \pi \cdot n}{N-1}\right) \quad \text { for } n=1,2 \ldots, N
$$

Wherein $N$ is the length of the data series (i.e. 4096).

3. Running an FFT procedure to calculate the Fourier coefficients $X(m)$ of the observed water depth time series $x(n)$ of length $N$. Each coefficient relates to a frequency interval $f(m)$ :

$$
\begin{gathered}
X(m)=\sum_{n=1}^{N} x(n) \cdot e^{-2 \pi i(m-1)(n-1) / N} \quad \text { for } m=1, \ldots, N \\
\quad f(m)=m \cdot f_{s} / N \quad \text { for } m=1, \ldots, N
\end{gathered}
$$

With $f_{s}$ representing the sampling frequency (i.e. $10 \mathrm{~Hz}$ ).

4. Calculate the pressure response factor $K_{p}$ in order to take account of the attenuation of the wave signal towards the bed. This factor depends on the water depth and wave length and hence can only be calculated after the FFT has been executed. Assuming linear wave theory $K_{p}[-]$ can be calculated as (CERC, 1984):

$$
K_{p}(m)=\frac{\cosh (k(m) \cdot z)}{\cosh (k(m) \cdot d)} \quad \text { for } m=1, \ldots, N
$$

With the wave number $k=2 \pi / L\left[\mathrm{~m}^{-1}\right]$ calculated for each frequency interval $f(m)$ of the Fourier coefficients. The water depth $d[\mathrm{~m}]$ and the elevation of the sensor above the bed $z[\mathrm{~m}]$ are assumed constant within each burst.

5. Calculate the one-sided periodogram $P$ from the Fourier coefficients:

$$
\begin{array}{ll}
P(m)=\frac{\left|X(m) \cdot K_{p}(m)^{-1}\right|^{2}}{f_{s} N} & \text { for } m=1, \frac{N}{2}+1 \\
P(m)=\frac{2 \cdot\left|X(m) \cdot K_{p}(m)^{-1}\right|^{2}}{f_{s} N} & \text { for } m=2, \ldots, \frac{N}{2}
\end{array}
$$

Only the first half of the Fourier coefficients is taken into account, as the second half consists of complex conjugates. 
6. Applying correction factor $C$ to account for the effect of the taper in step 2 and calculating the energy density spectrum $S$ :

$$
\begin{gathered}
C=\frac{N}{\sum_{n=1}^{N} w(n)^{2}} \\
S(f(m))=C \cdot P(m) \quad \text { with } m=1, \ldots, N / 2
\end{gathered}
$$

With $f(m)$ the frequency [Hz] of the $m^{\text {th }}$ component of the energy density spectrum $S\left[\mathrm{~m}^{2} \mathrm{~s}\right]$.

The results of this procedure were used to derive significant wave heights $\left(H_{s}[\mathrm{~m}]\right)$, root-meansquare wave heights $\left(H_{r m s}[\mathrm{~m}]\right)$, mean wave periods $\left(T_{m}[\mathrm{~s}]\right)$ and total wave energy $\left(E_{t o t}\left[\mathrm{~J} / \mathrm{m}^{2}\right]\right)$ for every burst of wave data:

$$
\begin{gathered}
E_{t o t}=\sum_{m=1}^{N / 2} S\left(f_{m}\right) \cdot \Delta f \cdot \rho g \\
H_{s}=4 \sqrt{m_{0}} \\
H_{r m s}=2 \sqrt{2 \cdot m_{0}} \\
T_{m}=m_{0} / m_{1}
\end{gathered}
$$

Where $\Delta f$ is the frequency bandwidth of the spectrum (i.e. $\left.f_{s} / N[\mathrm{~Hz}]\right)$ and $m_{0}$ and $m_{l}$ are the $0^{\text {th }}$ and $1^{\text {st }}$ spectral moments of the energy density spectrum:

$$
m_{a}=\sum_{m=1}^{N / 2} S\left(f_{m}\right) \cdot f_{m}{ }^{a} \cdot \Delta f \quad \text { with } a=0,1
$$

Subsequently, bursts have been selected for time spans during which the entire transects were flooded. This selection aims at assimilating coherent datasets of wave characteristics at the monitoring locations along each transect obtained during the same period and hence under the same conditions.

\section{RESULTS}

\section{Vegetation Density}

Figure 3 shows how the vegetation cover, expressed as \%o of the horizontal surface at a certain height, changes with height for each of the vegetation plots as indicated in the cross sections in Figure 1C-D. In general, these plots show a rapidly decreasing vegetation cover with increasing elevation. However, a significant difference exists between the findings for the plots in the Avicennia and Rhizophora zones. At $5 \mathrm{~cm}$ above the bed (i.e. the mean height of the pneumatophores) vegetation cover in the Avicennia plots is still fairly high (17-23\%) due to the dense coverage by pneumatophores varying from 300 up to 2200 pneumatophores $/ \mathrm{m}^{2}$ (see Figure 3). Above this dense layer of pneumatophores, vegetation cover suddenly decreases to less than $5 \%$ only, since at these levels vegetation mainly consists of stems. For the Rhizophora plots, the near bed vegetation density is of the same order, but shows some more spreading for the different plots (15-39\%). Moreover, the decrease of the woody elements over depth is much more gradual due to the characteristic architecture of these trees with many stilt roots gradually branching off into a dense network of small roots (up to 450 for a large tree) with a typical diameter of only a few cm's close to the bed (see Figure 3).

Integrating the vegetation cover over depth results in the vegetation density (expressed as volume$\%$ o). For the Palian transect vegetation densities in the forest front are significantly smaller than in the back of the forest with densities of $4.3 \%$ and $19 \%$ for the Avicennia and Rhizophora zones respectively. For the Kantang transect, densities within both plots in the Avicennia zone were $4.5 \%$ and in the Rhizophora zone the density was found to be 5.8\% and 9.3\% for the front and back plot 
respectively. So the increase in vegetation density along the Kantang transect is much less pronounced and does not correlate as much to the predominant vegetation type as along the Palian transect.
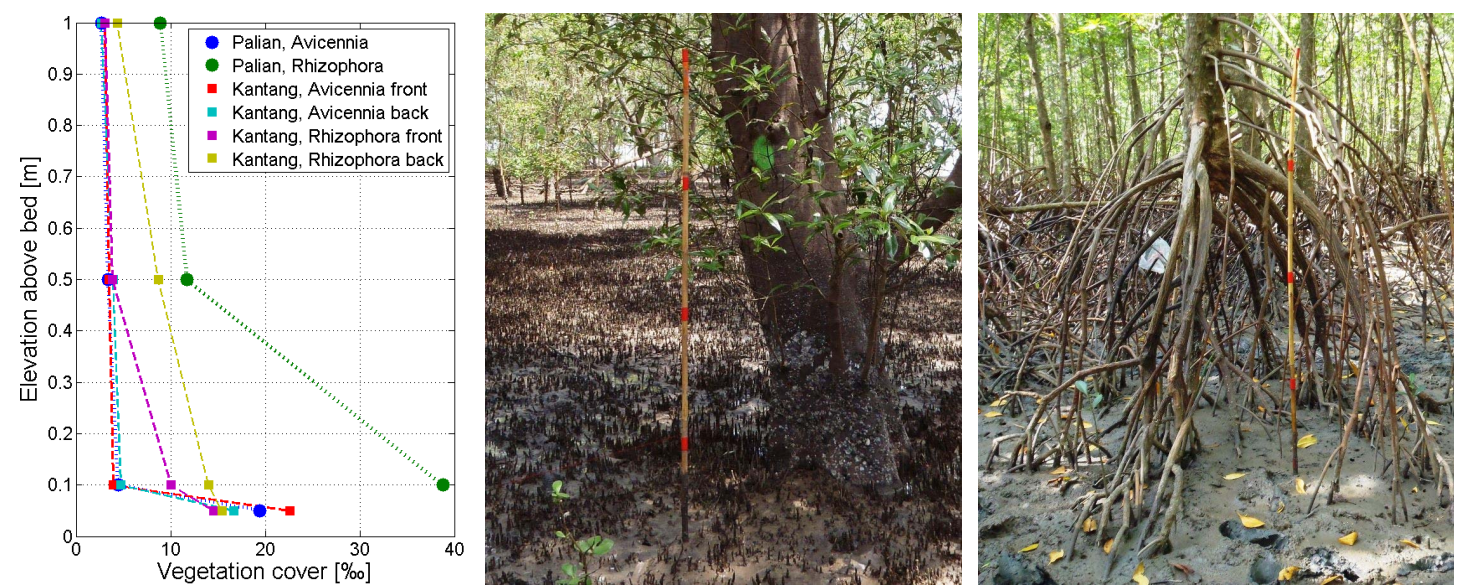

Figure 3. Variation of the vegetation coverage with elevation above the forest floor in \%o (left) and characteristic vegetation in the Avicennia zone (middle) and Rhizophora zone (right). The red tapes on the pole are each $50 \mathrm{~cm}$ apart and start at $50 \mathrm{~cm}$ above the bed.

\section{Wave Energy Density}

Selection of uniform sets of simultaneously obtained data resulted in a dataset containing 130 and 128 bursts respectively for the first and the second measurement campaign along the Kantang transect. Along the Palian transect, the subsequent campaigns resulted in 300 and 205 useful bursts. Figure 4 shows averaged wave energy density spectra for both transects during each deployment. During three of the deployments, data for some locations are missing due to malfunctioning sensors. The plots in Figure 4 highlight some distinct differences in the wave climates faced at both transects.

The wave spectra for the Kantang transect are largely uni-modal with wave periods mainly varying between 10-20 s. The wave spectra for the Palian transect, on the other hand, are bi-model showing major peaks for periods between 7-10 s and between 10-20 s. Moreover, the spectra for the first deployment along the Palian transect show a minor concentration of energy in waves with 3-5 s periods. Hence the Kantang transect is typically exposed to long swell waves, while the majority of the waves at the Palian transect are shorter sea waves.

Maximum energy densities faced along the Kantang transect are up to twice as high as the maxima along the Palian transect, indicating that the Kantang transect is exposed to higher waves. Together with the different modalities of the spectra, these features are caused by the different orientation of the transects. Since the Kantang transect is directly exposed to swell waves from the Andaman Sea, incident waves are at the lower end of the frequency spectrum for wind waves. The Palian transect, on the other hand, is fronted by an estuary with a shorter fetch so the incident waves are both shorter and lower.

Development of wave energy densities along the transects are apparent for both transects in the wave energy density spectra plotted in Figure 4. Waves longer than $10 \mathrm{~s}$ are hardly attenuated during three of the four deployments, while the parts of the spectra for frequencies $>0.1 \mathrm{~Hz}$ generally show decreasing energy density levels in the subsequent sensors along the transects during all deployments. It even appears that some energy is being transferred from relatively short waves $(>0.1 \mathrm{~Hz})$ to waves longer than $10 \mathrm{~s}$ during the Apr/May measurements at the Palian transect. Sensors towards the back of the forest show slightly increasing energy densities in the $0.05-0.1 \mathrm{~Hz}$ frequency range compared to the sensor in front, while energy densities at larger frequencies are decreasing towards the back of the forest. However, this trend is not generally observed in the data. 

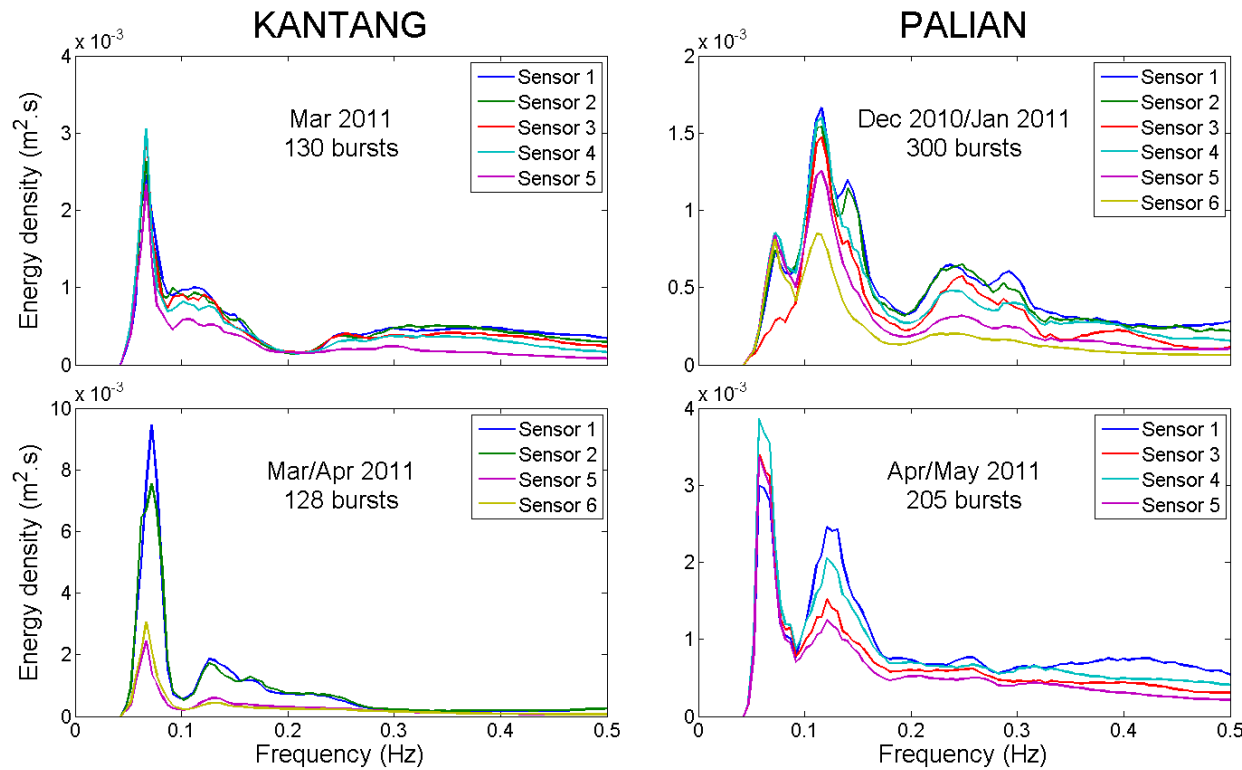

Figure 4. Averaged wave energy density spectra for concurrent deployment of sensors along each transect. Sensor numbers refer to the numbering of the positions in Figure 1. The number of bursts included in the averaged energy density spectra are indicated along with the moment of data collection.

\section{Wave Attenuation Along Transects}

Several wave characteristics have been derived from the obtained wave energy density spectra. The along-transect changes of these wave characteristics $\left(H_{s}, T_{m}\right.$ and $\left.E_{t o t}\right)$ are plotted in Figure 5 and Figure 6 for the Kantang and Palian transect respectively. The plotted statistics include both deployments along each of the transects, representing 258 bursts for the Kantang transect and 505 bursts for the Palian transect.

Typical incident waves at both transects do not exceed $10 \mathrm{~cm}$ in height. Between the first and last sensors along the transect, mean significant wave height gradually decreases from 7.4 to $4.6 \mathrm{~cm}$ at the Kantang transect. Waves propagating along the Palian transect show a smaller decrease in wave height along the transect; averaged wave heights decrease from $6.9 \mathrm{~cm}$ to $3.8 \mathrm{~cm}$ between the first and last sensor.

While the significant wave height decreases along both transects, mean wave periods are slightly increasing towards the back of the forest. As was shown by Figure 4 already, shorter waves (i.e. frequencies $>0.1 \mathrm{~Hz}$ ) loose more energy when propagating into the forest than the longer waves. Hence higher frequency waves get more effectively attenuated and gradually wash out when propagating into the forest, while longer (swell) waves hardly get attenuated. This gives rise to a gradual increase in the mean wave periods along the transects; mean wave periods increase from 4.6 to $5.3 \mathrm{~s}$ and from 3.5 to 5.0 s along the Kantang and the Palian transect respectively.

Due to the quadratic relation between wave height and wave energy, total wave energy along the transects shows a more pronounced decrease than wave heights. Along the Kantang transect, on average $63 \%$ of the total incident energy $\left(3.7 \mathrm{~J} / \mathrm{m}^{2}\right)$ gradually dissipates over the $246 \mathrm{~m}$ stretch between the first and last sensor. At Palian about $72 \%$ of the mean incident total wave energy $\left(3.8 \mathrm{~J} / \mathrm{m}^{2}\right)$ is attenuated between the first and last sensor, which are only $98 \mathrm{~m}$ apart along this transect. This attenuation of wave energy is fully caused by drag forces due to vegetation and bed roughness. Wave breaking does not contribute to wave energy losses along these transects as observed wave heights are ranging up to only $1 / 5^{\text {th }}$ of the simultaneously measured water depths (see Figure 5 and Figure 6).

In general, wave characteristics show a rather consistent change (i.e. decreasing wave heights and energies and increasing wave periods) along the Kantang transect. This pattern fits the gradual increase in vegetation densities and bottom elevation along this transect. Along the Palian transect the changes in wave properties are somewhat less constant. Remarkable is the slight increase in wave height (and energy) between the third and fourth sensors along the Palian transect. This is probably caused by the sudden increase of vegetation density just behind the fourth sensor, giving rise to reflection of waves against the relatively dense Rhizophora forest. 
Finally, a small sub-sample of the data retrieved at the Kantang transect is selected for a period during which the transect was exposed to severe storms. Data statistics for March 27 and 28 are plotted in Figure 7. During this period, only three sensors were functioning properly. Significant wave heights are exceeding $30 \mathrm{~cm}$ for the bursts during the most extreme conditions. Mean significant wave heights decrease from 14 to $6.5 \mathrm{~cm}$ between the first and fourth monitoring location along the transect, while $79 \%$ of the incident wave energy $\left(14 \mathrm{~J} / \mathrm{m}^{2}\right)$ is being attenuated along this sparsely vegetated stretch of only $142 \mathrm{~m}$. Nevertheless, attenuation still has to be ascribed to vegetation and bottom induced drag forces as wave heights do not exceed 0.5 times the water depth and hence will still not be breaking.

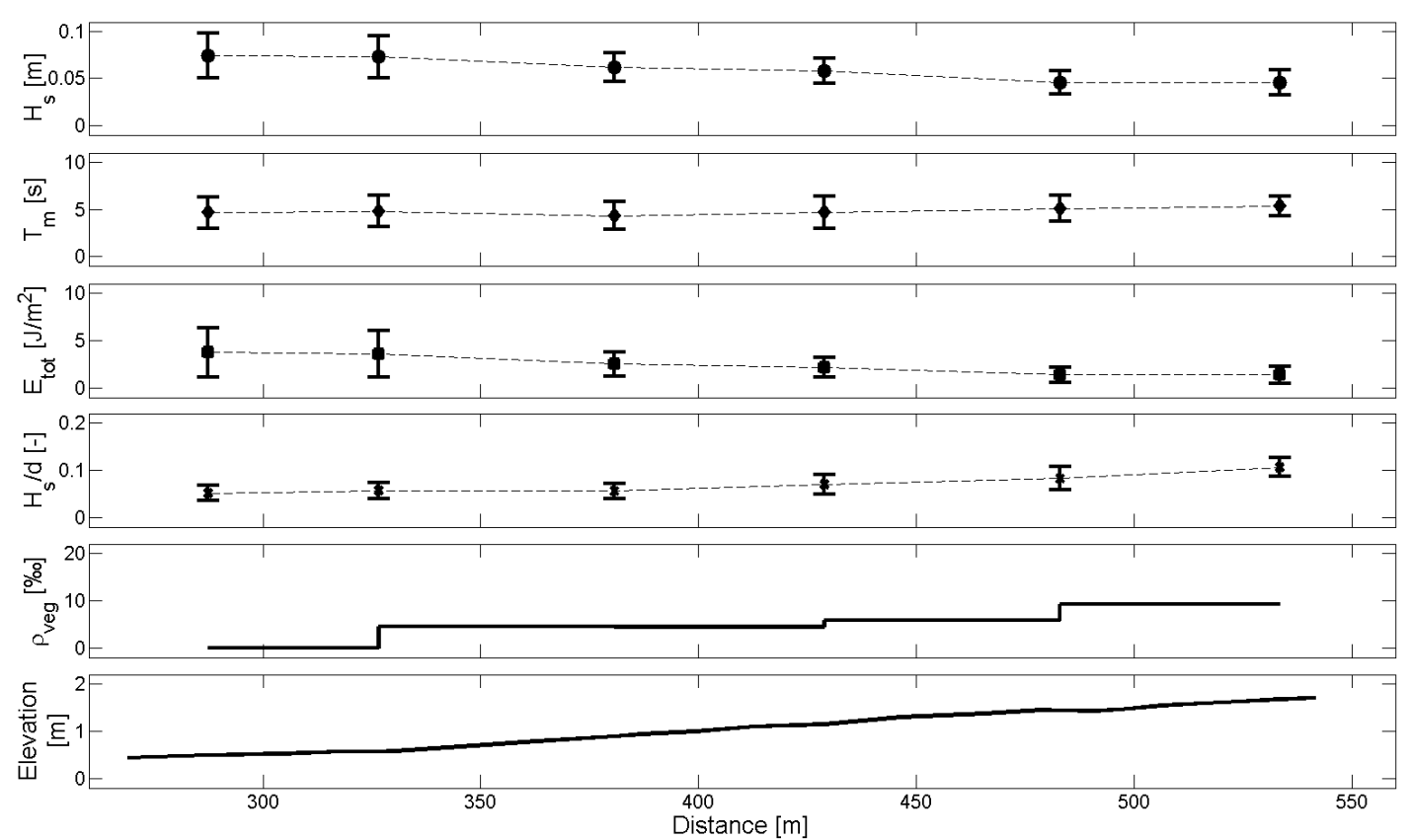

Figure 5. Wave characteristics (wave height $H_{s}$, wave period $T_{m}$, wave energy $E_{\text {tot }}$ and wave height divided by water depth $H_{s} / d$ ), vegetation densities $\left(\rho_{\text {veg }}\right)$ and bottom elevation observed along the Kantang transect are plotted in these panels (from top to bottom). Bar plots of the wave characteristics show the mean observed values plus/minus the standard deviation of the observations.

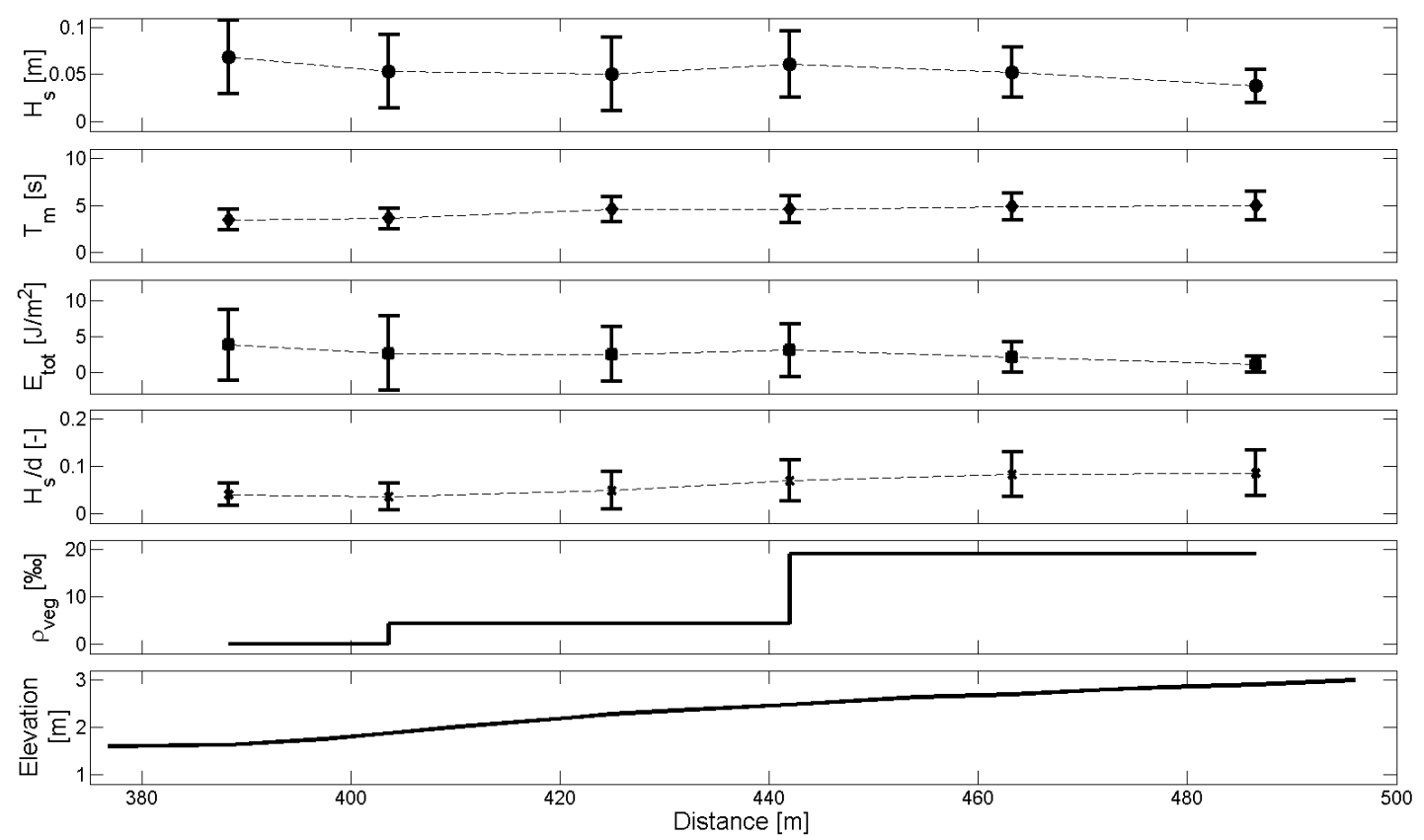

Figure 6. Same as Figure 5, but for the Palian transect. 


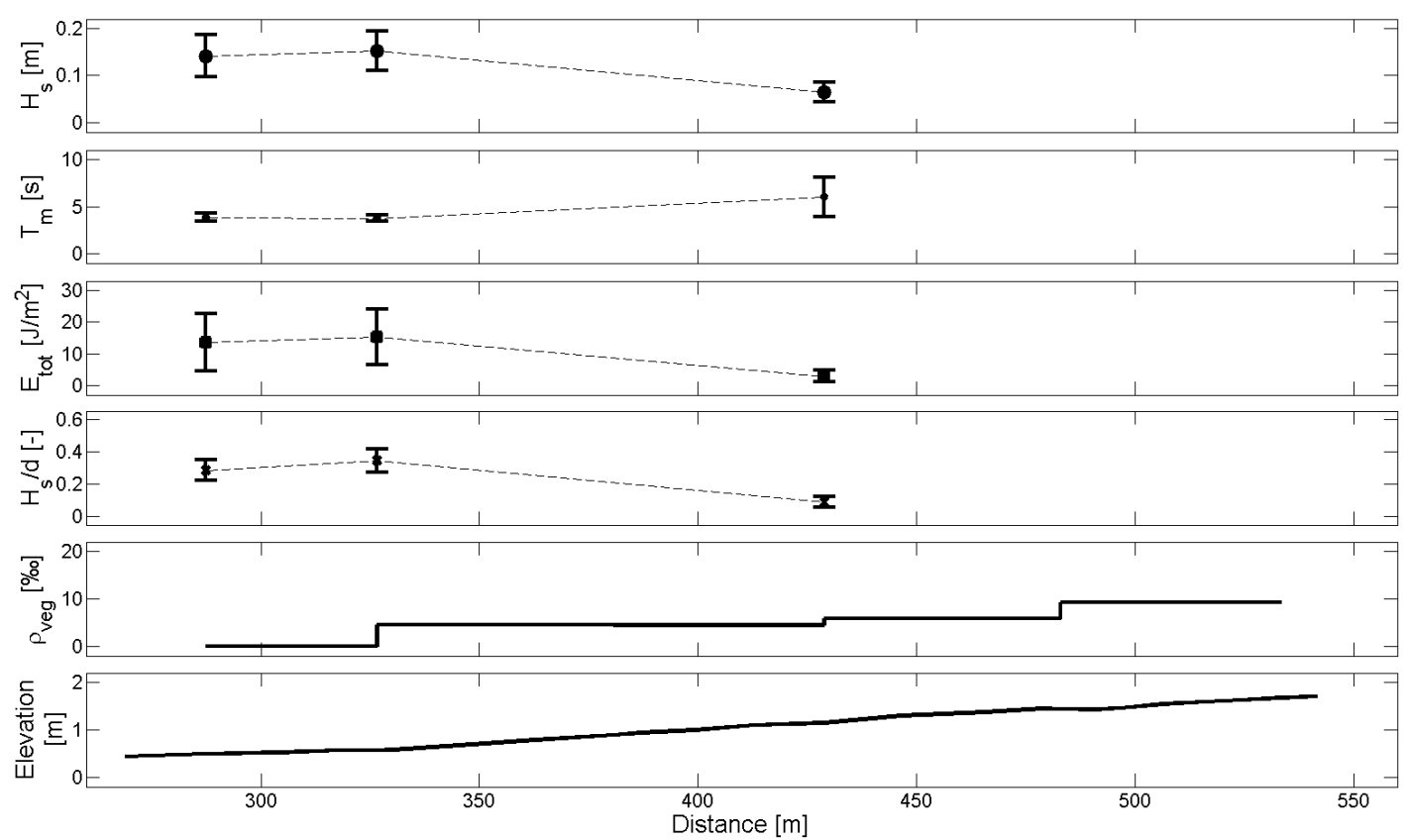

Figure 7. Same as Figure 5, but now for sub-set of the data comprising a two-day period during which the Kantang transect was exposed to a storm.

\section{Linking Wave Attenuation To Vegetation Densities}

Along with the decrease of wave heights and energies along both transects, deviations around the mean observed values are also decreasing further into the forest (see Figure 5, Figure 6 and Figure 7). This implies that higher-than-average wave heights and energies are reduced more effectively, while lower wave heights and energies are attenuated less effectively than the mean observed values. Hence the attenuating capacity of mangroves not only depends on the vegetation, but also on the wave conditions. With increasing wave heights and incident wave energy, the attenuation increases as well. To study this correlation, first the wave energy attenuation between any pair of sensor $\left(\Delta E_{t o t}\left[\mathrm{~J} / \mathrm{m}^{2}\right]\right)$ has been standardized to the energy attenuation over a distance of $1 \mathrm{~m}$ to $\Delta E_{t o t, 1 m}\left[\mathrm{~J} / \mathrm{m}^{2}\right]$ :

$$
\begin{array}{ll}
\Delta E_{\text {tot }}(a, b)=E_{\text {tot }}(b)-E_{\text {tot }}(a) & \text { for } a=1, \ldots, 5 \\
\Delta E_{t o t, 1 m}(a, b)=\Delta E_{t o t}(a, b) / L(a, b) & \text { for } b=2, \ldots, 6
\end{array}
$$

Wherein $a$ and $b$ represent the number/position of the first and second sensor of this pairwise comparison and $L(a, b)$ stands for the distance [m] between those two positions. The standardized energy attenuation is plotted versus the incident energy at the first sensor of any of these pairs (i.e. sensor $a$ ) in Figure 8 in order to quantify the correlation between energy attenuation and incident energy. Moreover, in order to isolate the impact of vegetation density in these correlations, distinction is made between attenuation rates retrieved from the mudflat $\left(\Delta E_{t o t, 1 m}(1,2)\right)$, within the Avicennia zone $\left(\Delta E_{t o t, 1 m}(2,3)\right.$ and $\left.\Delta E_{t o t, 1 m}(3,4)\right)$ and within the Rhizophora zone $\left(\Delta E_{t o t, 1 m}(4,5)\right.$ and $\left.\Delta E_{t o t, 1 m}(5,6)\right)$.

Looking at the results for the Kantang transect, it is observed that incident wave energies $E_{\text {tot }}$ are decreasing towards the back of the forest. This is related to the bed elevation of the forest, and hence the maximum water depths, as maximum total wave energy increases with the observed water depth (Figure 8, $r=0.51, p<0.01$ ). Standardized attenuation correlates fairly good with the incident wave energy with correlation coefficients $(r)$ of $0.32,0.41$ and 0.59 for the respective vegetation zones $(p<0.01$ for each zone). Moreover, linear fits show increasing positive gradients for the subsequent vegetation zones, indicating that higher attenuation values are found for the same incident wave energy when (denser) vegetation is present.

Results for the Palian transect in Figure 8 are less straightforward. Along this transect, maximum observed total wave energies do increase with water depth as well, but the correlation between wave energy and water depth is weak $(r=0.17)$. Standardized attenuation again correlates well with the total incident wave energy with correlation coefficients $(r)$ of $0.36,0.40$ and 0.93 for the respective 
vegetation zones ( $p<0.01$ for each zone). Positive gradients of linear fits are increasing much stronger throughout the subsequent vegetation zones than at the Kantang transect, especially in the Rhizophora zone. This is related to the much higher vegetation density observed in this zone.

At the same time, a double trend is observed in the attenuation calculated for the Avicennia zone at the Palian transect (Figure 8). Both positive and negative attenuation rates are faced within this zone. It is found that most positive attenuation rates are found for the first half of the Avicennia zone (between sensors 2 and 3), while most negative rates are occurring at the second half of this zone (between sensors 3 and 4) just in front of the Rhizophora zone. This trend of increasing (wave heights and) wave energy just in front of the dense Rhizophora forest has already been observed for this transect in the previous section (see Figure 5).
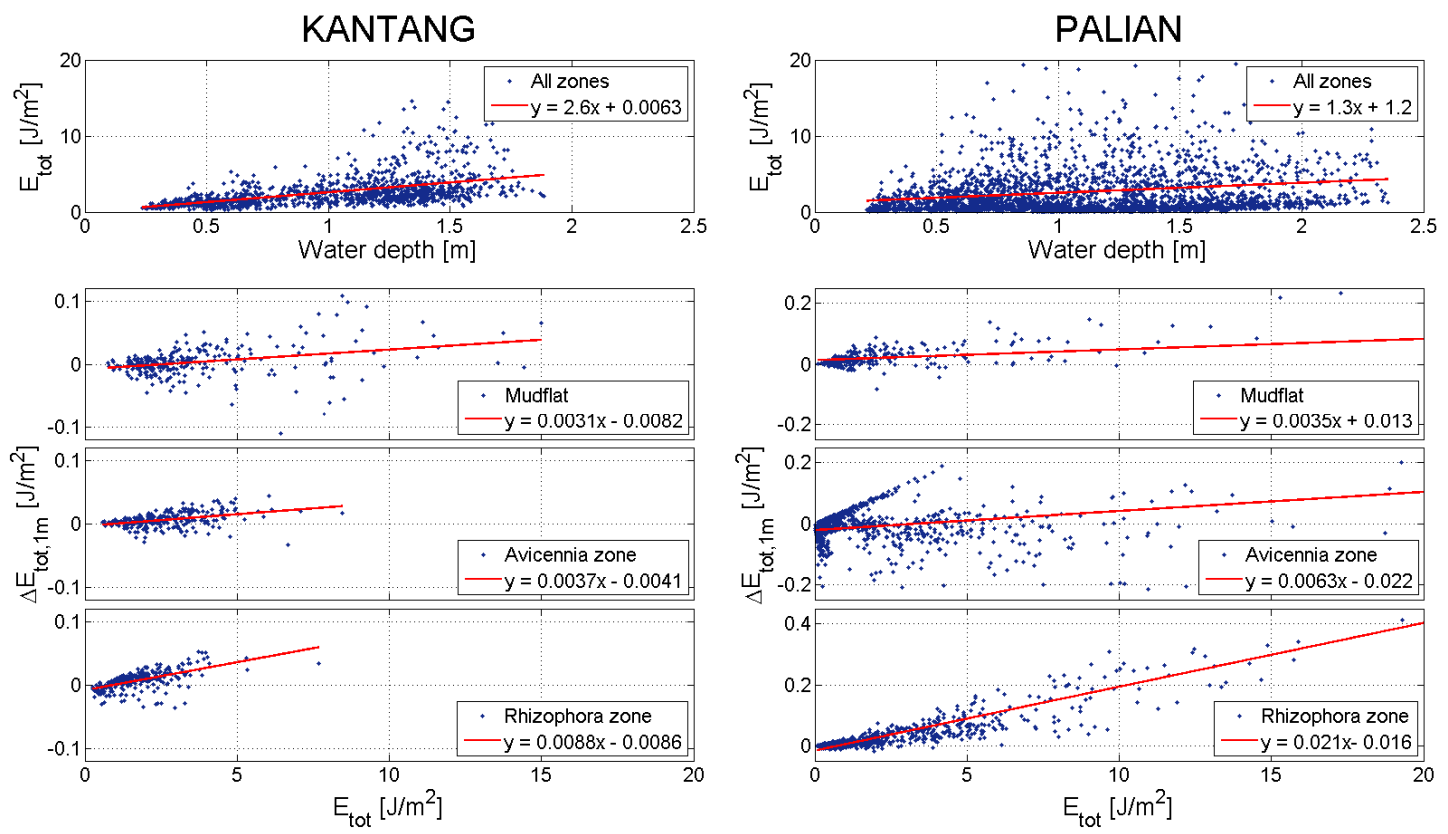

Figure 8. Correlations between total wave energy $E_{\text {tot }}$ and simultaneous water depths observed at any of the sensors are shown in the upper panes (Kantang left, Palian right). Per transect, standardized energy attenuation $\Delta E_{\text {tot, } 1 m}$ is correlated with the incident wave energy $E_{\text {tot }}$ per vegetation zone in the lower panes (mudflat, Avicennia and Rhizophora respectively).

From the previous findings it follows that correlating the standardized wave attenuation (as shown in Figure 8) with vegetation densities would result in a biased relation. Water depths are decreasing towards the (higher elevated) back of the forest and moreover the vegetation in front of the back forest also attenuates part of the wave energy. Hence the incident wave energy is lower in the denser vegetated areas at the landward ends of the transects. As energy attenuation was also shown to increase with higher incident wave energies, attenuation rates found for the denser vegetated parts of the transects are not as high as they would have been in case the incident wave energy would have been the same as the energy observed on the mudflat.

Therefore the dimensionless energy reduction rate $r_{E}$ is defined as the steepness of the fits in Figure 8:

$$
r_{E}=\frac{\partial \Delta E_{t o t, 1 m}}{\partial E_{t o t}}
$$

This parameter gives better insight as it is insensitive to the changing incident wave energies along the transects. These dimensionless wave reduction rates have been determined for every pair of sensors within each vegetation zone. So the data plotted in the bottom panels of Figure 8 have been subdivided for both the first and second sensor pair in the Avicennia and Rhizophora zones and a linear relation has been fitted to each of these data subsets. Figure 9 correlates the resulting energy reduction rates to the volumetric vegetation densities. These two parameters correlate significantly with a correlation 
coefficient $r$ of $0.94(p<0.01)$. A linear fit indicates an increasing energy reduction rate with increasing vegetation densities:

$$
r_{E}=0.00099 \cdot \rho_{v e g}+0.0013
$$

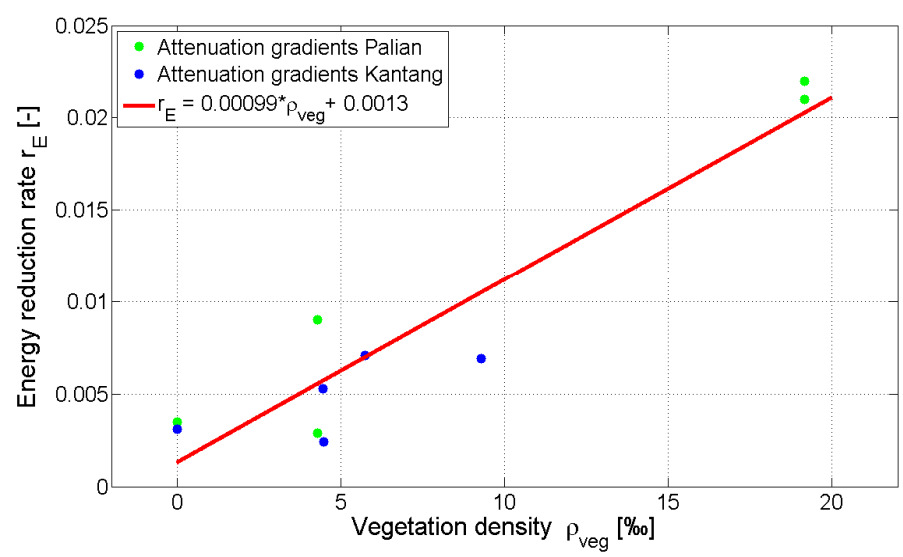

Figure 9. Wave energy reduction rates for each sensor pair in every vegetation zone are correlated with the volumetric vegetation densities in these zones.

The same analyses have also been applied to the (change of) wave heights along both transects. Changes of wave height between any pair of sensors are standardized by dividing them with the distance between the sensors and are subsequently correlated with the incident wave height at the sensor closest to the sea. Results are shown in Figure 10 and show the same trends as those observed in the analysis of the wave energy. The dimensionless wave reduction rate $r_{H}$ is defined similar to the energy reduction rate $r_{E}$, analogue to its definition by Mazda et al. (2006). This parameter typically varies from 0.001 to $0.014: r_{H}=2.8 \cdot 10^{-3} ; 2.0 \cdot 10^{-3} ; 4.1 \cdot 10^{-3} ; 5.4 \cdot 10^{-3} ; 8.7 \cdot 10^{-3}$ for the respective sensor pairs at Kantang and $r_{H}=1.9 \cdot 10^{-3} ; 0.5 \cdot 10^{-3} ; 7.8 \cdot 10^{-3} ; 13 \cdot 10^{-3} ; 14 \cdot 10^{-3}$ for the respective sensor pairs at Palian. This wave reduction rate correlates significantly with the vegetation density as well $(r=0.91$, $p<0.01)$ according to the equation:

$$
\begin{gathered}
r_{H}=\frac{\partial \Delta H_{1 m}}{\partial H} \\
r_{H}=0.00062 \cdot \rho_{v e g}+0.0016
\end{gathered}
$$

\section{DISCUSSION}

Wave data presented in this paper are in accordance with field observations presented in previous papers concerning wave periods but wave heights tend to be lower compared to some preceding studies. In a field campaign in the Red River Delta, Vietnam, Quartel et al. (2007) observed wave periods varying from 3.5 to $7 \mathrm{~s}$ and wave heights ranging from 5 to $30 \mathrm{~cm}$. Vo-Luong and Massel (2006; 2008) collected wave data along a transect in the Nang Hai mangrove forest in Vietnam and observed significant wave heights ranging up to $45 \mathrm{~cm}$ just in front of the forest, but within the forest significant wave heights were limited to $25 \mathrm{~cm}$ (the assumed wave period was $1.2 \mathrm{~s}$ ). In contrast, measurements in Cocoa Creek, Australia, and Iriomote Island, Japan, resolved wave periods varying between 1.5 and $5 \mathrm{~s}$ only, with wave energy densities of the order of $10^{-5}-10^{-4} \mathrm{~m}^{2} \mathrm{~s}$ for Cocoa Creek and Iriomote Island respectively (Brinkman et al., 1997; Massel et al., 1999). This is at least one order of magnitude smaller than the energy densities observed in the present paper, indicating that observed waves were even lower (no wave heights are presented). Brinkman (2006) also studied a transect in Oonoonba, Australia, finding wave periods between 3 and $12 \mathrm{~s}$ and wave energy densities of the order of $10^{-3} \mathrm{~m}^{2} \mathrm{~s}$, resembling the values found in the present study. So it can be concluded that in general the sheltered location of mangroves causes the wave heights to be rather low in all these studies. 

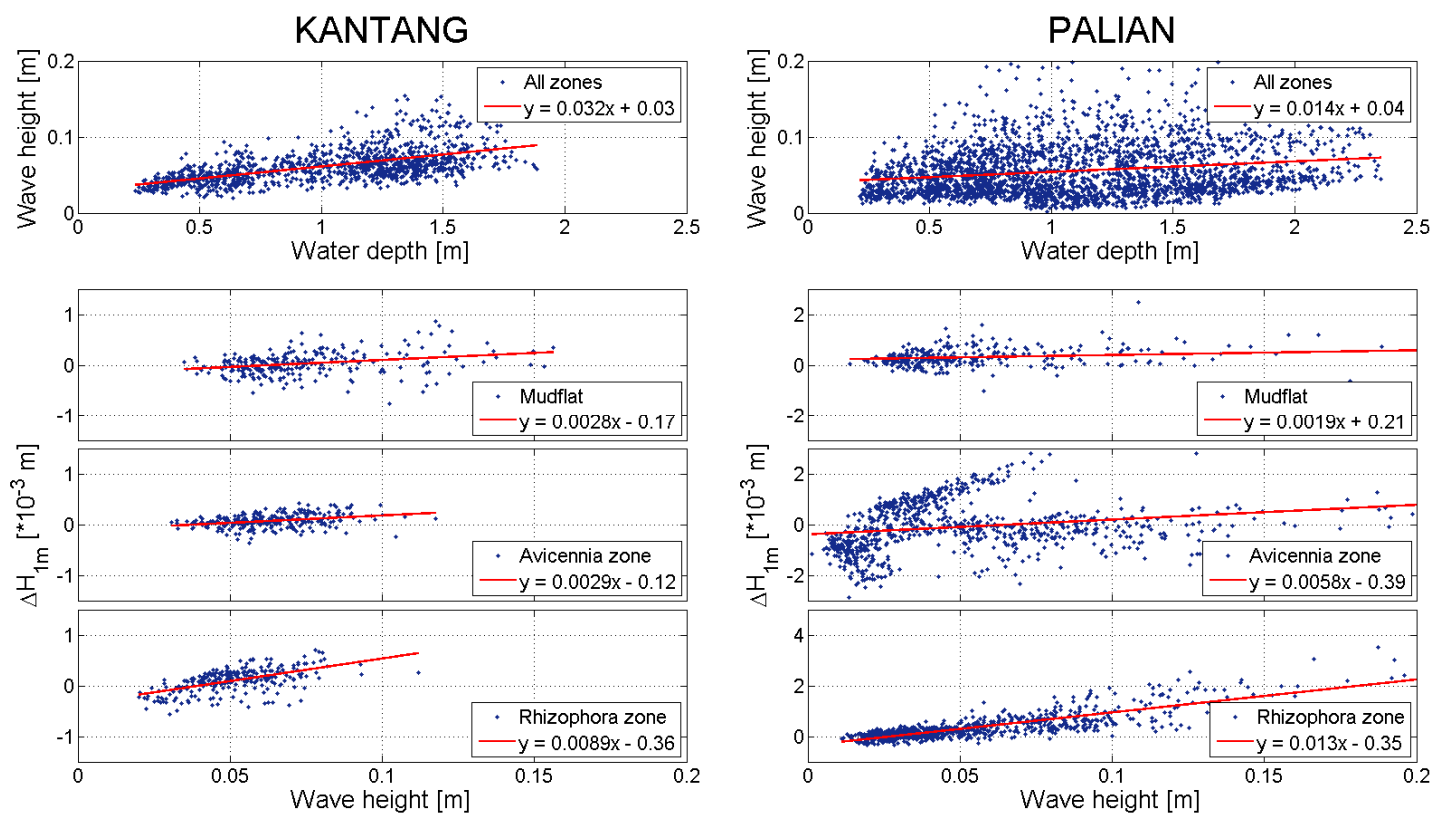

Figure 10. Correlation between wave height $\mathbf{H}$ and simultaneous water depths observed at any of the sensors are shown in the upper panes (Kantang left, Palian right). Per transect, standardized wave height reduction $\Delta H_{1 m}$ is correlated with the incident wave height $H$ per vegetation zone in the lower panes (mudflat, Avicennia and Rhizophora respectively).

Brinkman (2006) found reductions of total wave energy at the three previously mentioned sites (Cocoa, Oonoonba, Iriomote) of 64\%, 95\% and 71\% along transects of respectively $260 \mathrm{~m}, 40 \mathrm{~m}$ and $40 \mathrm{~m}$ in length. Along with these findings, significant wave heights were found to decrease by $50 \%$, $75 \%$ and $54 \%$ along these respective transects. The latter two reduction rates of both wave energy and height are quite high compared to the energy and wave height attenuation found in the present paper. Mean observed wave energy is decreasing with 63\% along the Kantang transect (246 m) and with 72\% along the Palian transect $(98 \mathrm{~m})$. Along the same stretches, mean wave heights are observed to decrease with 38\% and 45\% respectively. Mazda et al. (2006) found wave reduction rates of 0.0010.004 for a transect along the Vinh Quang coast, Vietnam, and Quartel et al. (2007) observed wave reduction rates of $0.004-0.012$ at their Red River site. These reduction rates compare well to the wave reduction rates of 0.002-0.009 along the Kantang transect and 0.001-0.014 along the Palian transect.

The spreading in the above summary of previously obtained field data underlines the variability in attenuation characteristics in different field sites. As shown in this study and by the foregoing overview, attenuation in mangroves strongly depends on the hydrodynamic conditions (incident wave energy) and the vegetation characteristics. This underlines the need for field measurements including hydrodynamics as well as vegetation characteristics, as was stated in the introduction, and has been a driving factor for the present study. Herein, a profound characterization plays a major role. A rough schematization based on the number of trees, tree height and leaf cover, as deployed by Bao (2011) is only appropriate for small trees of which the canopy will be flooded. Such a method is not appropriate for the large trees at the present study sites (up to $20 \mathrm{~m}$ high). Therefore, the volumetric approach previously deployed by Mazda et al. (1997b) has been adapted and deployed.

Next to the correlation of wave energy attenuation with vegetation densities (Figure 8 and Figure 9), attenuation rates have also been correlated with water depths. Due to the variation of vegetation densities along the vertical (see Figure 3), it is to be expected that attenuation rates decrease with increasing water depths. However, hardly any correlation was found to exist between wave attenuation and water depth, except for the fact that higher water depths facilitate higher incident wave energy and hence higher attenuation rates. This is probably due to the fact that for any of the observations, water levels exceeded the pneumatophores. Hence the very dense vegetation layer in the lower $10 \mathrm{~cm}$ above the bed was always fully inundated, reducing its energy attenuating capacity. At the same time, water levels never exceeded the full height of the extensive Rhizophora stilt root systems, so these stilt roots always added significantly to the drag forces exerted on the water. Nevertheless, the height of pneumatophores and stilt roots can differ quite a lot and these findings do not exclude the possibility of 
depth dependency of attenuation rates in different mangrove areas. Even at the same sites, attenuation is expected to increase significantly when water levels reach the canopy of the trees (starting at several meters above the bed).

Currently, all wave attenuation has been lumped. However, attenuation will be caused by drag forces exerted by the vegetation at one hand and by the bed at the other hand. It is important to distinguish the contribution of the mangroves to the wave attenuation, in comparison to a barren coast (Quartel et al., 2007). Moreover, the collected data will be of additional value if it were used to calibrate a numerical model (e.g. SWAN) for including the attenuating capacities of mangroves. Such a model could then be used for simulating different scenarios for the sites described in this paper, but probably for different sites as well.

\section{CONCLUSIONS}

This paper presents the results of an extensive, 6 months lasting field campaign in mangroves in southern Thailand. Two transects have been determined, showing different outlines and vegetation cover. Collection of wave data along these transects in combination with detailed vegetation measurements is unprecedented and is of great importance to the further development of knowledge on the attenuation of waves in mangrove vegetation.

The findings of this study indicate that vegetation densities are highly variable in both the vertical and the horizontal direction. Close to the bed, mangrove roots cover $20-40 \%$ of the area, while this coverage decreases rapidly at higher elevations. At the higher elevations, the dominant vegetation type plays a major role as Rhizophora stilt root systems are much more extensive than the pneumatophores of Avicennia and Sonneratia trees. Volumetric vegetation densities were found to be 4.3-4.5\%o in the Avicennia zones along both transects. Vegetation densities in the Rhizophora zones are higher; 5.89.3\% at the Kantang transect and $19 \%$ at the Palian transect.

The mean observed significant wave heights decrease with 38\% along the Kantang transect which is $246 \mathrm{~m}$ long and with $45 \%$ along the Palian transect which is only $98 \mathrm{~m}$ long. Along with these decreasing wave heights, total wave energy on average decreases with $63 \%$ and $72 \%$ along these transects respectively. The loss of wave energy is mainly restricted to the short wind waves $(<10 \mathrm{~s})$, since swell waves (10-20 s) tend to remain their energy or even gain energy by the attenuation of the shorter waves.

Energy attenuation is found to correlate significantly with the incident wave energy when results are subdivided according to different vegetation densities. The energy reduction rate $r_{E}$ is defined as the gradient of the relation between the energy attenuation and the incident energy. These energy reduction rates vary from 0.002 to 0.022 and show a significant positive correlation with increasing volumetric vegetation densities. The same is concluded for the wave reduction rate $r_{H}$, defined as the gradient of the relation between wave height reduction and incident wave heights. These rates range between 0.001-0.014 and also show a statistically significant increasing trend with increasing vegetation density.

\section{ACKNOWLEDGMENTS}

The authors gratefully acknowledge useful contributions to this work by C.J.L. Jeuken (Deltares/SDWA) and P.M.J. Herman (Royal NIOZ). The authors also acknowledge all assistance in planning, facilitating and executing fieldwork by D. Galli (National University of Singapore/SDWA), D.A. Friess (National University of Singapore/SDWA), E.L Webb (National University of Singapore/SDWA), C. Sudtongkong (Rajamangala University of Technology Srivijaya, Thailand), Katai, Dumrong and Siron. Fieldwork for this paper has been executed under the NRCT research permit 'Ecology and Hydrodynamics of Mangroves' (Project ID-2565). The authors gratefully acknowledge the support \& contributions of the Singapore-Delft Water Alliance (SDWA). The research presented in this work was carried out as part of the SDWA's Mangrove research program (R264-001-024-414).

\section{REFERENCES}

Alongi, D.M. 2008. Mangrove forests: Resilience, protection from tsunamis, and responses to global climate change, Estuarine, Coastal and Shelf Science, 76, 1-13.

Alongi, D.M. 2009. The Energetics of Mangrove Forests. Springer, Netherlands, 216 pp.

Anthony, E.J. 2004. Sediment dynamics and morphological stability of estuarine mangrove swamps in Sherbro Bay, West Africa, Marine Geology, 208, 207-224. 
Augustinus, P.G.E.F. 1995. Geomorphology and sedimentology of mangroves. In: G.M.E. Perillo (Ed.), Developments in Sedimentology, Elsevier, pp. 333-357.

Bao, T.Q. 2011. Effect of mangrove forest structures on wave attenuation in coastal Vietnam, Oceanologia, 53, 807-818.

Brinkman, R.M. 2006. Wave attenuation in mangrove forests: an investigation through field and theoretical studies. James Cook University, Townsville, 146 pp.

Brinkman, R.M., S.R. Massel, P.V. Ridd and K. Furukawa. 1997. Surface wave attenuation in mangrove forests. Pacific Coasts and Ports '97, Christchurch, New Zealand, pp. 941-946.

CERC. 1984. Shore protection manual, U.S. Army Corps of Engineers, Washington, DC, 337 pp.

Danielsen, F., M.K. Sørensen, M.F. Olwig, V. Selvam, F. Parish, N.D. Burgess, T. Hiraishi, V.M. Karunagaran, M.S. Rasmussen, L.B. Hansen, A. Quarto and N. Suryadiputra. 2005. The Asian Tsunami: A Protective Role for Coastal Vegetation, Science, 310, 643.

FAO. 2007. The world's mangroves, 1980-2005. Food and Agriculture Organization of the United Nations, Rome, 77 pp.

Hegge, B.J. and G. Masselink. 1996. Spectral analysis of geomorphic time series: auto-spectrum, Earth Surface Processes and Landforms, 21, 1021-1040.

Massel, S.R., K. Furukawa and R.M. Brinkman. 1999. Surface wave propagation in mangrove forests, Fluid Dynamics Research, 24, 219-249.

Mazda, Y., M. Magi, Y. Ikeda, T. Kurokawa and T. Asano. 2006. Wave reduction in a mangrove forest dominated by Sonneratia sp., Wetlands Ecology and Management, 14, 365-378.

Mazda, Y., M. Magi, M. Kogo and P.N. Hong. 1997a. Mangroves as a coastal protection from waves in the Tong King delta, Vietnam, Mangroves and Salt Marshes, 1, 127-135.

Mazda, Y., E. Wolanski, B. King, A. Sase, D. Ohtsuka and M. Magi. 1997b. Drag force due to vegetation in mangrove swamps, Mangroves and Salt Marshes, 1, 193-199.

McIvor, A.L., I. Möller, T. Spencer and M. Spalding. 2012. Reduction of wind and swell waves by mangroves, Cambridge Coastal Research Unit, Cambridge, 27 pp.

Möller, I. 2012. Bio-physical linkages in coastal wetlands - implications for coastal protection. In: W.M. Kranenburg, E.M. Horstman and K.M. Wijnberg (Eds.), NCK-days 2012; Crossing borders in coastal research. University of Twente, Enschede, The Netherlands, pp. 51-60.

Quartel, S., A. Kroon, P.G.E.F. Augustinus, P. Van Santen and N.H. Tri. 2007. Wave attenuation in coastal mangroves in the Red River Delta, Vietnam, Journal of Asian Earth Sciences, 29, 576584.

Spalding, M., M. Kainuma and L. Collins. 2010. World Atlas of Mangroves. Earthscan, London, UK, 319 pp.

Suzuki, T., M. Zijlema, B. Burger, M.C. Meijer and S. Narayan. 2012. Wave dissipation by vegetation with layer schematization in SWAN, Coastal Engineering, 59, 64-71.

Van Santen, P., P. Augustinus, B.M. Janssen-Stelder, S. Quartel and N.H. Tri. 2007. Sedimentation in an estuarine mangrove system, Journal of Asian Earth Sciences, 29, 566-575.

Vo-Luong, H.P. and S.R. Massel. 2006. Experiments on wave motion and suspended sediment concentration at Nang Hai, Can Gio mangrove forest, Southern Vietnam, Oceanologia, 48, 23-40.

Vo-Luong, P. and S. Massel. 2008. Energy dissipation in non-uniform mangrove forests of arbitrary depth, Journal of Marine Systems, 74, 603-622.

Woodroffe, C.D. 1992. Mangrove sediments and geomorphology. In: A.I. Robertson and D.M. Alongi (Eds.), Tropical mangrove ecosystems, American Geophysical Union, Washington DC, pp. 741. 